\title{
Etiology and Antibiogram of Subclinical Mastitis in Cows of Puri District, India
}

\author{
P. Sahoo, N. Sahoo* and S. Biswal \\ Department of Epidemiology and Preventive Medicine, College of Veterinary \\ Science and Animal Husbandry, Odisha University of Agriculture and Technology, \\ Bhubaneswar -751003, India \\ *Corresponding author
}

\section{A B S T R A C T}

\begin{tabular}{|l|}
\hline Key w or d s \\
Gram positive \\
bacteria, dairy \\
cows, In vitro
\end{tabular}

Subclinical mastitis (SCM), predominantly caused by Gram positive bacteria, continues to be a global problem of dairy cows including India with negative impact on economic growth as well as public health. SCM was detected in 283 cross-bred Jersey milch cows between $2^{\text {nd }}$ to $5^{\text {th }}$ lactation from a milk-shed village of Odisha on the basis of cow-side test (Modified California Mastitis Test) and cultural examination. Polymerase chain reaction using universal $16 \mathrm{~S}$ primers followed by Sangers sequencing helped to identify Staphylococcus aureus in maximum (49.8\%) cows followed by Streptococcus uberis (14.8\%), Streptococcus agalactiae (8.1\%), Streptococcus dysagalactiae $(7.8 \%)$ and Streptococcus pyogenes (3.8\%), Escherichia coli $(2.1 \%)$, Proteus sp $(1.8 \%)$ and Klebsiella pneumonia (1.4\%). In vitro antibiotic sensitivity test was performed by disc diffusion method. Anitibiotics showing sensitivity to more than 90 per cent of milk samples were ceftiofur $(98.3 \%)$, cefuroxime $(97.34 \%)$, gentamicin $(95.52 \%)$, ceftizoxime $(94.09 \%)$, cephalexin $(92.47 \%)$ and cefoperazone $(90.91 \%)$.

\section{Introduction}

Bovine mastitis, a multi-factorial disease, is caused by more than 200 serotypes/biotypes (1). However, bacteria are still considered as the predominant pathogens. A large number of dairy cattle throughout the world suffer from mastitis with huge economic loss. The subclinical form of the disease is $30-40$ times more prevalent than its clinical stage (2). Antibiotics are being used with variable degree of efficacy. However, their use is not free from public health hazards due to unwanted antibiotic residues in milk as well as antimicrobial resistance. A rational approach to combat the situation is use of effective therapy and appropriate control measures thereof. Keeping the above facts back drop, the study was designed to unveil the bacterial etiology and in vitro antimicrobial sensitivity pattern of cows suffering from subclinical mastitis (SCM) in a milk producing society.

\section{Materials and Methods}

Cross-bred Jersey milch cows from a milk-shed village of Odisha (Coordinate: 
$19.9870^{\circ} \mathrm{N}$ and $86.0160^{\circ} \mathrm{E}$ ) were included in the study with the owners' consent. All the cows were between $2^{\text {nd }}$ to $5^{\text {th }}$ lactation. The study period stretched October-December, 2019. Apparently healthy cows without any visible abnormality in the milk and/or gland were randomly screened for detection of SCM. About 20 milliliter of milk sample was pooled from all functional quarters in a dry clean container for diagnosis of SCM through cow-side test. Modified California Mastitis Test (MCMT) was performed as per the standard procedure for differential diagnosis (3). MCMT reagent was freshly prepared taking 3\% solution of sodium lauryl sulphate in distill water and indicator bromocresol purple. Equal amount of MCMT reagent and milk was taken on the paddle/ petridish and mixed in a swirling manner. Results were read within 15 seconds. Appearance of slime of different degree considered positive reaction.

Approximately 2.0 milliliter of milk sample was collected aseptically in sterile vial from cow found positive to MCMT $(n=291)$ for microbiological examination. Milk sample was inoculated into nutrient broth and incubated at $37^{\circ} \mathrm{C}$. After 24 hours of incubation streaking was done in nutrient agar and incubated aerobically at $37{ }^{0} \mathrm{C}$ for 24 hours. Milk samples showing colonies in agar plate were considered positive for SCM $(n=283)$. Gram staining was performed to ascertain the morphological features. DNA extracted from pure bacterial colonies was subjected to polymerase chain reaction using universal $16 \mathrm{~S}$ primers followed by Sangers sequencing for identification of bacterial pathogen. Qiagen make kits were used for extraction of DNA.

The in vitro antibiotic sensitivity test was performed by disc diffusion method (4). Twenty-one antimicrobial discs such as Gentamicin, Enrofloxacin, Azithromycin,
Neomycin, Streptomycin, Amikacin, Oxyetracycline, Cloxacillin, Colistin, Bacitracin, Penicillin G, Amoxyclav, Ceftizoxime, Cefoperazone, Ceftriaxone \& Sulbactam, Piperacillin \& Tazobactum, Ciprofloxacin, Cefuroxime, Amoxycillin, Ampicillin and Cefotaxime were used for in vitro study. The zones of inhibition were measured up to the nearest $\mathrm{mm}$ (including the disc) and interpreted from the standard chart provided by the manufacturer as sensitive $(\mathrm{S})$, resistant (R) or intermediately resistant (I).

\section{Results and Discussion}

A total of 283 pooled milk samples showed bacterial growth, either in single $(96.1 \%)$ or mixed $(3.9 \%)$ form. The remaining $8(2.7 \%)$ samples did not show any indication of bacterial growth within 48 hours and such milk samples were regarded as either sterile or associated with nonbacterial pathogens. Based on the sequencing results, the pathogens were identified with more than $97 \%$ homology. The spectrum of pathogens thus identified is depicted in the table. Most common infectious agent causing of SCM in our study was Staphylococcus aureus which constituted half of the samples $(49.8 \%)$. It is stated that $S$. aureus is the potential cause of bovine subclinical mastitis $(5,6)$. Four streptococcal species isolated from the SCM positive milk samples were Streptococcus uberis (14.8\%), Streptococcus agalactiae (8.1\%), Streptococcus dysagalactiae (7.8\%) and Streptococcus pyogenes (3.8\%). The isolation of various Streptococccus spp. from mastitic milk samples has been reported by various authors $(6,7)$. The entry of Streptococcus spp. may be assisted by cowto-cow transmission possibly via the milker's hands.

In the present study, Escherichia coli was identified in $2.1 \%$ of milk samples. E. coli might have been transmitted from the cow's 
environment and infected the udder via the teat canal (8). E. coli is incriminated to be the cause of mastitis in dairy cows mainly around parturition and during early lactation (9). The observation regarding the isolation of Pseudomonas aeruginosa (9/283) is in agreement with the earlier reports $(5,10)$. This pathogen is an opportunistic organism causing mastitis in cows and has been grouped as an environmental pathogen (1). Uncommon mastitis pathogens like Klebsiella pneumoniae, considered as environmental pathogens, was recorded in the present study in 1.4 per cent cows. This corroborated the reports of Ramprabhu et al., (2004). Presence of Proteus spp. to an extent of 1.8 per cent is supported by the earlier report (11). Authors opined Proteus spp. as an uncommon mastitis pathogen of cows (1).

Association of Staphylococcus aureus with Streptococcus agalactiae and/or Escherichia coli was recorded in $3.9 \%(11 / 283)$ cows. Occurrence of this mixed bacterial infection was found to be significantly $(\mathrm{p}<0.05)$ lower than the single bacterial infection $(96.1 \%)$ which is supported by the previous findings
(12).

Study revealed that the Gram positive bacteria (84.0\%) causing SCM dominated that of Gram negative bacteria $(16.0 \%)$. The variation in the involvement of a wide range of pathogens and their proportion in subclinical mastitis could be the outcome of the interaction of the pathogens, hosts and its environment. This could be linked with housing system, climatic condition, production level, stage of lactation, calving interval, milking methods and hygiene.

Selection of suitable chemotherapeutic agent is considered as the key of a mastitis control program. The antimicrobials commercially available in the market for veterinary use as parenteral and intramammary preparations include ceftiofur, gentamicin, azithromycin, neomycin, streptomycin, ceftizoxime, cefoperazone, cefuroxime, cephalexin, ceftriaxone, ceftriaxone/sulbactam, ampicillin, amoxycillin, penicillin $\mathrm{G}$, colistin, cloxacillin, bacitracin, chloramphenicol, tetracycline and ciprofloxacin, hence included in the present in vitro study.

Table.1 Different bacterial isolates recovered from milk samples positive to subclinical mastitis in district Puri, Odisha $(\mathrm{n}=283)$

\begin{tabular}{|l|c|}
\hline \begin{tabular}{|} 
Bacteria isolated from milk samples positive for \\
SCM
\end{tabular} & No. of isolates \\
\hline Staphylococcus aureus & $141(49.8)$ \\
\hline Streptococcus uberis & $42(14.8)$ \\
\hline Streptococcus agalactiae & $23(8.1)$ \\
\hline Streptococcus dysagalactiae & $22(7.8)$ \\
\hline Streptococcus pyogenes & $10(3.8)$ \\
\hline Pseudomonas aeruginosa & $9(3.2)$ \\
\hline Escherichia coli & $6(2.1)$ \\
\hline Klebsiella pneumoniae & $4(1.4)$ \\
\hline Proteus sp. & $5(1.8)$ \\
\hline Mixed & $11(3.9)$ \\
\hline
\end{tabular}

*Figure in parenthesis indicate percentage 
The antibiogram pattern revealed that majority of the milk samples positive to SCM were sensitive to ceftiofur $(98.32 \%)$ followed by cefuroxime $(97.34 \%)$, gentamicin (95.52\%), ceftizoxime $(94.09 \%)$, cephalexin (92.47\%), cefoperazone (90.91\%), azithromycin (85.09\%), ceftriaxone/ sulbactam $(84.59 \%)$, ceftriaxone $(83.23 \%)$, bacitracin $(81.79 \%)$, neomycin $(77.08 \%)$ and ciprofloxacin $(72.03 \%)$.

Poor degree of sensitivity was recorded to penicillin G (8.66\%), colistin (14.02\%), cloxacillin (20.26\%), chloramphenicol (38.58\%), ampicillin (45.22\%), amoxicillin $(48.38 \%)$, streptomycin $(50.56 \%)$ and tetracycline $(51.31 \%)$.

Sensitivity to ceftriaxone, gentamicin ciprofloxacin, chloramphenicol, cephalexin, ceftiofur, azithromycin has also been reported earlier $(13,14,15,16)$, Resistance to penicillin G, ampicilin and amoxicillin, streptomycin, tetracycline cloxacillin has also been reported by $(17,18,19,20)$.

The study suggests that use of resistant group of drugs as listed above would not only fail to bring recovery rather, may complicate the situation further. In other words, the antibiotics under former group with high degree of sensitivity could be prescribed at first instance in absence of the scope of in vitro sensitivity test.

The use of broad spectrum antibiotics and antibiotic combinations may influence the resistance of mastitis pathogens. Development of resistance against a particular antibiotic in a specific region may be due to its frequent and long-term use (Moon et al., 2007).

In addition, administration of the extra labeled use of antibiotic and presence of infected cow in herds could facilitate development of drug resistance.

\section{Acknowledgment}

Authors are thankful to the Veterinary Officers and Livestock Inspectors for their cooperation during the period of study.

\section{References}

Balakrishnan, G., Unny, M., Dorairanjan, D. and Subramanian, M. 2004. Studies on bovine mastitis at Namakkal. Indian Veterinary Journal, 81 (10): 11661167.

Bhanderi, B. M. and Garg, M. R. 2012. A study on reducing the incidence of sub-clinical in dairy cows by feeding a vitamins and minerals based strategic feed supplement. Indian Journal of Dairy Science, 65 (5): 388-392.

Cruickshank, R. Duguid, J.P., Mavmion, B.P. and Sarin, R.H.A. 1975. Medical Microbiology, 12th edn. Churchill, Livingstone, London.

Das, K., Tiwari, R. K. S. and Shrivastav, D. K. 2010. Techniques for evaluation of medicinal plant products as antimicrobial agent: Current methods and future trends. Journal of Medicinal Plants Research, 4 (2): 104-111.

Erskine, R. J. 2001. Food animal production medicine, $3^{\text {rd }}$ Edition, W. B. Sounders Company, pp-397-435.

Jeykumar, M., Vinodkumar, G., Bashir, B. P. and Krovvidi, S. 2013. Antibiogram of mastitis pathogens in the milk of crossbred cows in Namakkal District, Tamilnadu. Veterinary World, 6 (6): 354-356.

Moon, J. S., Lee, A. R., Kang, H. M., Lee, E. S. and Kim, M. N. 2007. Phenotypic and genetic antibiogram of methicillin-resistant staphylococci isolated from bovine mastitis in Korea. Journal of Dairy Science, 90 (3): 1176-1185. 
Mounir, M. S., Muharram, M. M., Ibrahim M. A., Ehab, M. S. Y., Hashim 2010. Molecular Detection of Genes Encoding Virulence Determinants in Staphyloccous aureus Strains isolated from Bovine Mastitis. Journal of Applied Sciences Research, 6 (2):121128.

Nagal, K. B., Sharma, M. and Katoch, R. C. 1999. Etiology of Bovine mastitis in and Palampur in Himanchal Pradesh. Indian Journal of Animal Science, 63 (3): 150-152.

Patnaik, S., Prasad, A. and Ganguly, S. 2014. Biochemical characterization and antibiogram of staphylococcal microorganisms associated with subclinical mastitis in lactating crossbred cows. Animal Science Reporter, 8 (4): 123-129.

Radostits, O. M., Gay, C. C., Hinchcliff, K. W. and Constable, P. D. 2007. Veterinary medicine: a text book of the diseases of cattle, horses, sheep, pigs and goats. $10^{\text {th }}$ edition. WB Saunders Co. Ltd. Philadelphia. Pp 673-762.

Rahman, M. M., Islam, M. R., Uddin, M. B. and Aktaruzzaman, M. 2010. Prevalence of subclinical mastitis in dairy cows reared in Sylhet district of Bangladesh. International Journal of Biological Research, 1 (2): 23-28.

Ramprabhu, R., Jairam, Karthik, A., Ravikanth, K., Maini, S. and Adarsh. 2014. Evaluation of regular teat sanitization control measures for prevention of subclinical mastitis in cattle. American Journal of Phytomedicine and Clinical Therapeutics, 2 (10):1212-1216.

Ranjan, R., Gupta, M. K., Singh, S. and Kumar, S. 2010. Current trend of drug sensitivity in bovine mastitis. Veterinary World, 3 (1):17-20.
Saei, H. D. 2012. Coa types and Antimicrobial resistance profile of Staphylococcus aureus isolates from cases of bovine mastitis. Comparative Clinical Pathology, 21 (3): 1-7.

Schlam, O.W. and Noorland, D.O. 1957. Experiments and observations leading to the development of California mastitis test. Joural of American Veterinary Medical Association, 130: 199-204.

Srinivasan, V., Gillespie, B. E. Lewis, M. J., Nguyen, L. T., Headrick, S. I., Schukken, Y. H. and Oliver, S. P. (2007). Phenotypic and genotypic antimicrobial resistance patterns of 20 Escherichia coli isolated from dairy cows with mastitis. Veterinary Microbiology, 124 (3-4): 319-328.

Vijayalakshmi, P. and Prathaban, S. 2007. Antibiotic selection in bovine mastitis. Indian Journal of Veterinary Medicine, 27 (1): 49-51.

Wenz, J. R., Barrington, G. M., Garry, F. B., Ellis, R. P. and Magnuson, R. J. 2006. Escherichia coli isolates' Serotypes, Genotypes, and Virulence Genes and clinical Coliform Mastitis Severity. Journal of Dairy Science, 89 (9): 3408-3412.

Zeedan, G. S. G., Abdalhamed, A. M., Abdeen, E., Ottai, M. E., Abdel-Shafy, S. 2014 Evaluation of antibacterial effect of some Sinai medicinal plant extracts on bacteria isolated from bovine mastitis. Veterinary World, 7 (11): 991-998.

Zeryehun, T., Aya, T. and Bayecha, R. 2013. Study on prevalence, bacterial pathogens and associated risk factors of bovine mastitis in small holder dairy farms in and around Addis Ababa, Ethiopia. The Journal of Animal and Plant Sciences, 23 (1): 5055. 


\section{How to cite this article:}

Sahoo. P., N. Sahoo and Biswal. S. 2020. Etiology and Antibiogram of Subclinical Mastitis in Cows of Puri District, India. Int.J.Curr.Microbiol.App.Sci. 9(07): 374-379. doi: https://doi.org/10.20546/ijcmas.2020.907.040 